\title{
Connexins: substrates and regulators of autophagy
}

\author{
Jegan lyyathurai ${ }^{1}$, Jean-Paul Decuypere ${ }^{2}$, Luc Leybaert $^{3}$, Catheleyne D'hondt and Geert Bultynck ${ }^{1 *}$
}

From International Gap Junction Conference 2015

Valparaiso, Chile. 28 March - 2 April 2015

\begin{abstract}
Connexins mediate intercellular communication by assembling into hexameric channel complexes that act as hemichannels and gap junction channels. Most connexins are characterized by a very rapid turn-over in a variety of cell systems. The regulation of connexin turn-over by phosphorylation and ubiquitination events has been well documented. Moreover, different pathways have been implicated in connexin degradation, including proteasomal and lysosomal-based pathways. Only recently, autophagy emerged as an important connexin-degradation pathway for different connexin isoforms. As such, conditions well known to induce autophagy have an immediate impact on the connexin-expression levels. This is not only limited to experimental conditions but also several pathophysiological conditions associated with autophagy (dys)function affect connexin levels and their presence at the cell surface as gap junctions. Finally, connexins are not only substrates of autophagy but also emerge as regulators of the autophagy process. In particular, several connexin isoforms appear to recruit pre-autophagosomal autophagy-related proteins, including Atg16 and PI3K-complex components, to the plasma membrane, thereby limiting their availability and capacity for regulating autophagy.
\end{abstract}

Keywords: Autophagy, Connexins, Degradation, Regulation

\section{Background}

\section{A short overview of the autophagy process}

Autophagy (meaning "to eat oneself") is a term to describe the intracellular processes responsible for the delivery of the cell's own macromolecules to the lysosomes (or vacuoles) for degradation and recycling [1]. Three main types of autophagy can be distinguished based on their mechanism of delivery. In microautophagy, direct delivery happens through invagination of the lysosomal membrane, while chaperone-mediated autophagy relies on molecular chaperones and lysosome-associated membrane protein 2 LAMP2 to guide misfolded proteins to the lysosomes. The best studied type of autophagy, macroautophagy (hereafter referred to as "autophagy"), involves the transport and delivery of intracellular macromolecules or organellar fragments to the lysosomes inside double-membranous

\footnotetext{
* Correspondence: geert.bultynck@med.kuleuven.be

${ }^{1} \mathrm{KU}$ Leuven, Laboratory of Molecular and Cellular Signaling, Department Cellular and Molecular Medicine, Campus Gasthuisberg O/N-I bus 802, Herestraat 49, B-3000 Leuven, Belgium

Full list of author information is available at the end of the article
}

vesicles (autophagosomes). Due to their relatively large size $(0.5-1.5 \mu \mathrm{m}$ in mammalian cells [2]), autophagosomes were already discovered by transmission electron microscopy in the early sixties and the term "autophagy" launched by Nobel Prize-winning lysosomal expert Christian de Duve in 1963 [3]. However, its importance became only acknowledged in 1999, when Levine and co-workers discovered that a critical autophagy protein, Beclin 1, is a tumor suppressor [4]. This seminal work and further investigation established autophagy as a crucial player in cellular life and death during stress and disease. Indeed, upon nutritional, hypoxic, chemical or mechanical stress, autophagy is often stimulated, leading to enhanced degradation and recycling of molecular components. This way, possibly toxic damaged macromolecules, aggregates or organelles can be swiftly removed, especially those that are too large to be degraded by the proteasome or when the proteasomal degradation is blocked [5]. Moreover, lysosome-dependent autophagic recycling creates a new pool of cellular building blocks to be incorporated into the required anti-stress proteins. This is particularly convenient during nutrient deprivation, when non-selective 
bulk recycling of macromolecules ensures the availability of amino acids and cellular survival. In contrast, specific autophagic degradation of protein aggregates or organelles (e.g. mitochondria, a process termed mitophagy) is mediated by specific proteins tagging and sequestering polyubiquitin chains or damaged organelles. As such, it is clear that autophagy is a self-protective process that removes possible toxic cell death-inducing signals and enhances survival. However, in certain situations, autophagy may actually provoke cell death. Although autophagy-dependent cell death is likely less frequent than pro-survival autophagy and while its mechanistic details are still unclear, it is a clinically relevant phenomenon (e.g. upon ischemia) [6-8].

To ensure that the formation, transport and fusion of autophagosomes is correctly executed, a network of molecular pathways and proteins are involved (Fig. 1). Many of these players are shared with the endocytic pathway [9]. However, the autophagic pathway also contains a set of autophagy-specific proteins (Atg proteins) that function in the formation of the double membranous structure (phagophore), its subsequent elongation and closure into an autophagosome and the sequestration of its cargo $[10,11]$. The origin of the phagophore is still debated, with different organelles postulated as candidates as source of this lipid bilayer [12]. This likely depends on the type of stress that induces autophagy and the material that needs to be degraded (specific organelles or structures or nonselective cytoplasmic in bulk degradation). At the endoplasmic reticulum (ER), clear observations have been made of the phagophore gradually originating and protruding from PtdIns(3)P-rich sites called omegasomes [13, 14]. This is mediated by the phosphoinositide 3-kinase (PI3K) Class III

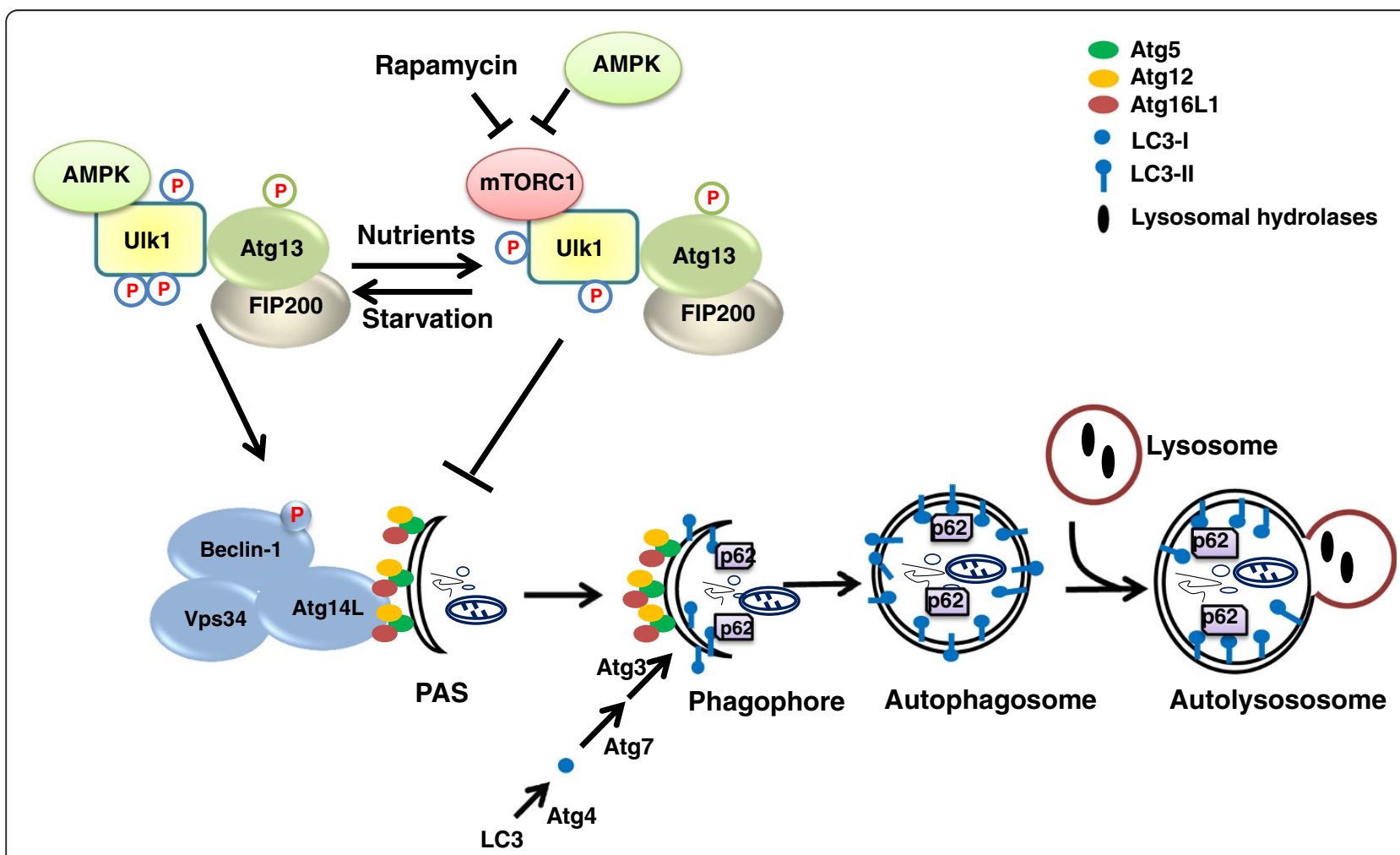

Fig. 1 Macroautophagy is a major recycling pathway for long-lived proteins, protein aggregates and organelles. Autophagy induction is controlled by the AMPK/mTOR-signaling axis. In nutrient-rich conditions, AMPK activity is low and mTOR activity is high, thereby suppressing the autophagic pathway. Upon nutrient starvation and/or energy deprivation, AMPK activity is high, causing the inhibition of mTOR (directly and indirectly via the TSC1/2-Rheb GTPase pathway) and activation of the ULK1 complex involving a complex network of phosphorylations. mTOR inhibition and autophagy activation can also be achieved in nutrient-rich conditions using chemical mTOR inhibitors like rapamycin. Activation of the ULK1 complex contributes to the activation of the class III PI3K complex (Atg14L/Beclin 1 (Atg6)Nps34 and the Vps34-regulatory protein Vps15 (not shown)) by phosphorylating Beclin 1, producing Ptdlns(3)P from PtIns at the pre-autophagosomal structures (PAS) necessary for the formation of the phagophore. This structure then elongates into a double-membranous vesicle, the autophagosome, by recruitment of the Atg12/Atg5/Atg16 complex and the lipidation of LC3-I into phosphatidylethanolamine-conjugated LC3-II. LC3-II formation involves the production of LC3-I by Atg4-mediated proteolytic cleavage of LC3 and the action of E1-like ligases (Atg7), E2-like ligases (Atg3) and E3-like ligase complexes (Atg12/Atg5/Atg16L1). Furthermore, ubiquitin-binding proteins like p62 can bind LC3, thereby linking ubiquitinated proteins to LC3-II and targeting them for autophagic degradation. The Atg12/Atg5/Atg16 complex present in the outer membrane dissociates from mature autophagosomes, which then fuse with the lysosomes, degrading the inner membrane and the cargo present in the autophagosomes via luminal hydrolysases and subsequently releasing the digested material via permeases back into the cytosol. The fusion of autophagosomes with lysosomes can also involve endosomes, leading to intermediate amphisome formation 
complex, consisting of (among others) Vps34, Vps15, Beclin 1 (Atg6) and Atg14L, which phosphorylates PtdIns to PtdIns(3)P. The PtdIns(3)P signal recruits several proteins (e.g. WIPI1 and2 (Atg18) [15] that induce the protrusion of the phagophore from the ER membranes. PI3K Class III activity is regulated by the nature of its interacting partners (including anti-apoptotic proteins $\mathrm{Bcl}-2$ and $\mathrm{Bcl}-\mathrm{X}_{\mathrm{L}}[16$, 17]) and by the ULK $1 / 2$ complex [18]. The latter consists of ULK1/2, Atg13 and FIP200 and mediates the response of autophagy towards nutrient availability and energy status, as it is regulated by the nutrient sensing kinase mTOR and the energy sensing AMP-dependent kinase AMPK, respectively. mTOR inhibits the ULK1/2 complex by phosphorylation when amino acids and growth factors are abundant. When nutrients are scarce however, mTOR activity is repressed and ULK1/2 active. Upon energy deprivation, AMPK phosphorylates ULK1/2 at different sites than mTOR, activating the complex [19], which stimulates PI3K Class III and triggers the formation of the phagophore. AMPK also inhibits mTOR activity by phosphorylating TSC1/TSC2 (tuberous sclerosis complex 1 and 2), thereby suppressing RHEB (Ras homologue enriched in brain) activity [20]. Further elongation of the phagophore is mediated by delivery of novel lipids transported by lipid carrier protein Atg9 [21], and by two ubiquitin-like reaction processes that are dependent on Atg7 [10, 22]. First, Atg 5 is covalently linked Atg12 by Atg7 (E1-like) and Atg10 (E2-like). The Atg5-Atg12 complex then binds Atg16L1, resulting in an Atg12-Atg5Atg16L1 complex that attaches to the autophagosomal membranes. Second, LC3-I is generated from the LC3 precursor mediated by proteolytic cleavage by Atg 4 and becomes lipidated in a series of ubiquitin-like reactions executed by E1-like (Atg7), E2-like (Atg3) and E3-like (Atg12-Atg5-Atg16L1) enzymes, resulting in LC3-II [11]. These reactions are crucial for the autophagy process, as Atg5-, Atg7-deficient mice and cells lack autophagic features [23, 24], although in specific tissues, Atg5 and Atg7-independent autophagy has been described [25]. LC3-II attaches to the autophagosomal membrane. This is exploited to determine the amount of autophagosomes by LC3-II detection. However, this does not necessarily reflect autophagic activity, since an inhibition of autophagosomelysosome fusion too can lead to an accumulation (and thus increase) of autophagosomes [26]. As such, LC3 data are often obtained in the absence and presence of lysosomal inhibitors and combined with experiments determining the levels of Sqstm1/p62, a long-lived protein, in order to carefully assess autophagic flux. This autophagy receptor links the cargo (e.g. polyubiquitin) to LC3-II at the autophagosomal membranes to be sequestered. Ultimately, p62 is degraded in the lysosomes, making its levels a valuable marker for the autophagic degradation rate [27].
Here, we will focus on the emerging role of autophagy as a novel connexin-turnover pathway with a brief summary of the earlier work implicating proteasomal and endosomal/lysosomal pathways for which we would like to refer to the many excellent and recent reviews on this topic published elsewhere [28-31].

\section{Connexin turnover and degradation by proteasomal and lysosomal pathways}

Connexin proteins, together with pannexins and CALHM1, form the basis for intercellular communication between cells and cell types in different tissues and organs [32, 33]. Hexameric connexin structures, called "connexons", form the functional units, being unopposed hemichannels or head-to-head docked gap junctions, providing flux pathways for a variety of ions, amino acids, nucleotides, metabolites and signaling molecules with molecular weights below $1.5 \mathrm{kDa}$ and small RNA molecules. Cx43, which represents the $43-\mathrm{kDa}$ connexin protein, is the most abundant connexin ubiquitously expressed in a plethora of tissues and organs. As gap junctions, connexins control a plethora of cellular and physiological processes, including the regulation of cell growth, migration, apoptosis, and cell signaling [34-37]. Gap junction dysregulation has been implicated in different pathophysiological conditions, including ischemia/ reperfusion in the heart, epilepsy, inflammation, neurodegeneration and myocardial infarctions [38-40]. Different mutations in connexin-encoding genes causing dysfunctional, mislocalized or downregulated gap junctions have been linked to human diseases such as cardiovascular diseases, congenital deafness, skin diseases, myelin-related diseases and cataracts [41-43]. Recently, hemichannels too have been emerging as important signaling hubs not only in pathophysiology (like ischemia reperfusion in brain and heart tissues), but also in physiology [44], like in fear memory consolidation in astroglia of the basolateral amygdala [45], in osteocyte viability important for bone structure, integrity and function $[46,47]$ and as natural oncosuppressors that counteract cancer growth and metastasis to the bone [48].

Importantly, connexin gap junction complexes are very dynamically different regulated in a variety of physiological and pathophysiological conditions in different cell types and systems (reviewed in [49]). In comparison to other membrane proteins characterized by half-lives between 17 and $100 \mathrm{~h}$, the turnover of connexin proteins is very rapid, between 1.5 and $5 \mathrm{~h}$ in various cell lines, cell types and tissue [49]. Rapid degradation may be an important mechanism for adjusting intercellular coupling of cells under normal and pathophysiological conditions. As an exception, a subpopulation of connexins expressed in the lens, like Cx45.6, Cx46 and Cx56 has a prolonged half-life (up to days) [49]. The turnover of connexin gap junctions is also dynamically regulated in response to physiological 
and pathophysiological conditions, including the response to EGF, phorbolesters or injury. This involves a wellcharacterized cascade of phosphorylation events [50]. For instance, Akt phosphorylation on Cx43 Ser373 promotes Cx43 gap junction assembly in an open state in response to EGF/injury, which is followed by a MAPK-mediated phosphorylation of Ser278/Ser282, closing gap junction, and a Src-mediated phosphorylation of Tyr247 causing Cx43 gap junction internalization [50, 51]. Degradation of Cx43 gap junctions may occur via the degradation of the "oldest subdomains" (i.e. containing the "oldest proteins") within the gap junction or via the internalization of the complete gap junction in a double membranous structure, called an "annular" junction or "connexisome" [50, 51]. This internalization of $\mathrm{Cx} 43$ gap junctions occurs at least in part via small endocytic double-membrane vesicles [52] in a clathrin-dependent manner [53, 54]. A plethora of studies revealed that the degradation of $\mathrm{Cx} 43$ proteins involve proteasomal and lysosomal pathways, including autophagy. The dynamic regulation of $\mathrm{Cx} 43$ gap junction size and levels by phosphorylation events triggered by physiological and pathophysiological stimuli is discussed elsewhere in different excellent reviews by others [50, 51].

Seminal work by Beyer and his team showed a prominent role for the ubiquitin-dependent proteasome as a major connexin-turnover pathway in normal conditions and stress conditions like heat stress [55]. Inhibitors of the proteasome significantly increased the half-life of $\mathrm{Cx} 43$ proteins in pulse-chase experiments. Besides pharmacological approaches, his team also used genetic-based approaches thereby elegantly comparing the turnover of Cx43 in E36 chinese hamster ovary cells and in E36 cells containing a temperature-sensitive version of the ubiquitin-activating protein, E1 (ts-E36). The ts-E36 cells are defective in the proteasomal degradation of short-lived or abnormal proteins at high temperatures $\left(39^{\circ} \mathrm{C}\right)$ but not at low temperatures $\left(30{ }^{\circ} \mathrm{C}\right)$. While $\mathrm{Cx} 43$-protein levels were similar in E36 and ts-E36 cells at low temperatures, Cx43-protein levels were prominently higher in ts-E36 cells than in wildtype E36 cells at high temperatures. The decline of $\mathrm{Cx} 43$ in E36 cells could be rescued by proteasomal inhibitors. Consistent with these findings, Cx43-ubiquitin conjugates could be identified in lysates of E36 cells treated with proteasomal inhibitors. A similar role for proteasomal degradation of Cx43 was described in rat heart-derived BWEM cells in which the loss of plasmalemmal $\mathrm{Cx} 43$ triggered by treating the cells with brefeldin A or monensin could be prevented by proteasomal inhibitors. Follow-up studies based on primary cultures from neonatal rat ventricular myocytes demonstrated that heat stress could enhance Cx43 degradation by the proteasome [56]. Interestingly, heat shock protein 70 , upregulated in response to heat stress, emerged as a protective factor preventing $\mathrm{Cx} 43$ degradation upon repeated heat stress stimuli.

The proteasome not only appears to be important for plasmalemmal $\mathrm{Cx} 43$ degradation, but likely assists in the ER-associated degradation (ERAD) mechanism (Fig. 2) of Cx43 dislocated from the ER of cells exposed to cellular stress (like in cells exposed to the reducing agent DTT) $[28,57]$. Further molecular studies provided evidence that ER-localized Cx43 could directly interact with a $75-\mathrm{kDa}$ protein $[58,59]$, named Cx43-interacting protein of 75 $\mathrm{kDa}$ or CIP75. This protein belongs to the ubiquitin-like (UbL) and ubiquitin-associated (UBA) domain protein family [60]. UBL/UBA-domain-containing proteins serve as shuttle/adapter proteins interacting on the one hand with ubiquitinated targets and on the other hand with the Rpn1 and Rpn10 subunits of the 19S regulatory particle,

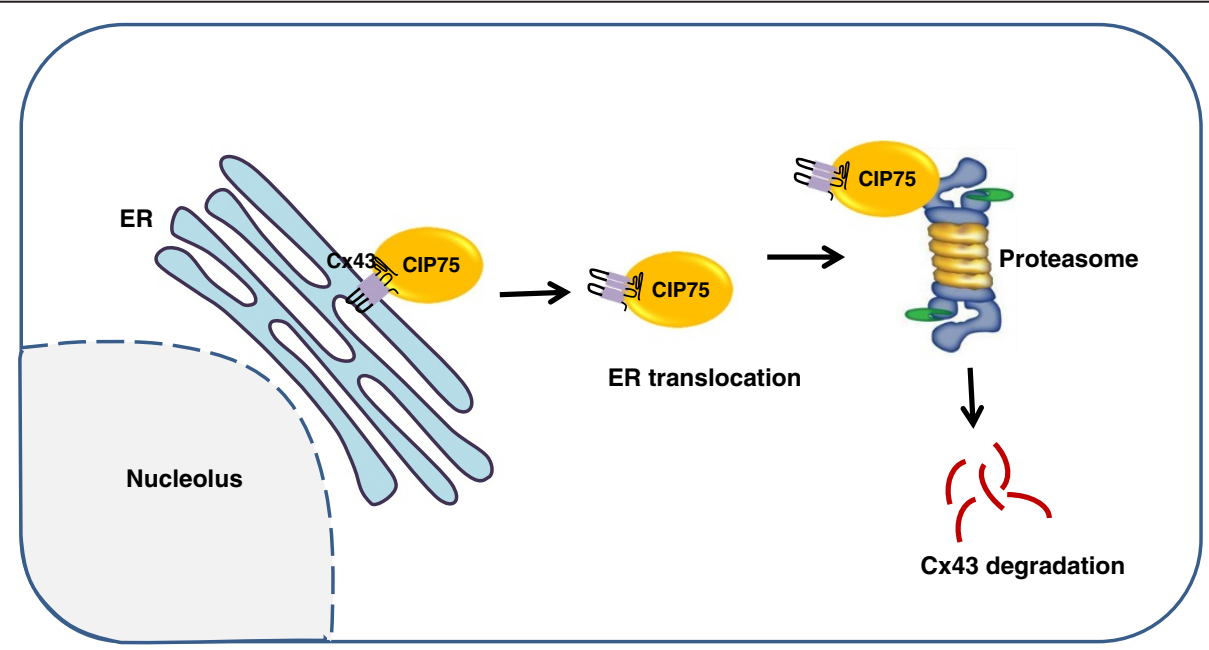

Fig. 2 Proteasomal degradation of Cx43 via ERAD: CIP75 binds to the C-terminal tail of ER-localized Cx43 via its UBA domain, and then facilitates the translocation of CX43 from the ER membrane into the cytosol. This complex interacts with 195 proteasome subunit via the CIP75 UBL domain, leads to the proteasomal degradation 
which together with the $20 \mathrm{~S}$ core particle forms the $26 \mathrm{~S}$ proteasome holoenzyme [58, 60]. Here, the UBA domain of CIP75 directly bound to the carboxyl terminus (CT) of Cx43 via a low-affinity interaction ( $K_{d}$ of about $\left.300 \mu \mathrm{M}\right)$, involving several regions within the intrinsically disorder part of the CT tail of Cx43 [61]. Further studies confirmed the presence of a multi-protein complex involving ERlocalized Cx43/CIP75/Rpn1/Rpn10 [62] in which CIP75 is essential for the interaction of $\mathrm{Cx} 43$ with the proteasomal components. CIP75 controlled Cx43 half-life, which increased in the absence of CIP75 and decreased upon CIP75 overexpression [58]. CIP75-induced Cx43 degradation could be prevented by proteasomal inhibitors. Interestingly, although CIP75 directly interacts with different ubiquitinated proteins, including the well-documented p27 (Cip/Kip family of cyclin dependent kinase inhibitor $1 \mathrm{~B}$ (CDKN1B)), to direct them to the proteasome for degradation, the interaction of CIP75 with ER-localized Cx43 occurred in an ubiquitin-independent manner [59]. Indeed, ER-localized Cx43 co-immunoprecipitated with CIP75 was not ubiquitinated, while immunoprecipitation of ubiquitinated proteins did not yield any Cx43. This finding was corroborated by experiments showing the binding of CIP75 to lysine-mutated Cx43, void of potential ubiquitinacceptor sites. Further experiments indicated that the interaction of CIP75 with Cx43 was increased upon misfolding of the $\mathrm{Cx} 43$ protein, either induced by mutations or by DTT [62]. Hence, CIP75 was proposed to facilitate the dislocation of $\mathrm{Cx} 43$ from the ER membranes into the cytosol, where it can be targeted to the proteasome for degradation by associating with the Rpn1 and Rpn10 components [62]. Very recently, the role of CIP75 in the proteasomal degradation of connexin proteins appeared not to be limited to the Cx43 isoform, but also impacted the degradation of other connexin isoforms, including $\mathrm{Cx} 40$ and Cx45 [61]. Similarly as for Cx43, the UBA domain of CIP75 was found to directly interact with the CT regions of $\mathrm{Cx} 40$ and $\mathrm{Cx} 45$ via low-affinity interactions involving several intrinsically disordered regions, which were not conserved among the different Cx43, Cx40 and Cx45 proteins. Consistent with these molecular findings, CIP75 levels affected the degradation of $\mathrm{Cx} 40$ and $\mathrm{C} \times 45$ proteins, in which CIP75 shRNAs augmented Cx40- and Cx45protein levels, likely by hampering their proteasomal degradation via ERAD. This is supported by the fact that cells expressing ER-targeted $\mathrm{Cx} 40$ or $\mathrm{Cx} 45$, treated with brefeldin A/DTT to induce $\mathrm{Cx} 40$ or $\mathrm{Cx} 45$ misfolding and degradation by ERAD, displayed augmented Cx40/ CIP75 or Cx45/CIP75-complex formation and colocalization at the ER membranes. Besides Cx40, Cx43 and $\mathrm{Cx} 45$, also $\mathrm{Cx} 32$ appears to be degraded via the proteasome involving ERAD, but this likely involves the canonical ubiquitination pathway of Cx32 [57, 63, 64]. This appears to be supported by biochemical evidence that CIP75 could be co-immunoprecipitated with cellular Cx32 but not with the bacterially expressed and purified CT of Cx32 [61]. Proteasomal degradation has also been implicated in the turnover of pathological mutant connexin channels that are inherently unstable [65]. For instance, a frame shift mutation in Cx50 causing recessive congenital cataract resulted in an unstable Cx50 protein that is rapidly degraded via ERAD and the proteasome, thereby reducing $\mathrm{Cx} 50$ gap junctions and impairing intercellular communication [65]. Epoxomicin, a proteasomal inhibitor, prevented the degradation of the mutant Cx50 protein, increasing Cx50-protein levels and their presence as functional gap junctions, capable of restoring intercellular coupling.

However, early on in connexin research, it became also very clear that lysosomal pathways contributed to the connexin degradation, potentially as a minor component in normal physiological conditions, but gaining more importance upon stress $[55,66]$. Lysosomotropic amines slightly increased the half-life of $\mathrm{Cx} 43$ in response to heat stress [55]. However, follow-up studies showed that endogenous Cx43 levels were about 4-fold higher in BWEM cells exposed to proteosomal or lysosomal inhibitors than in untreated BWEM cells [66]. In brefeldin A-induced Cx43degradation experiments, proteasomal and lysosomal inhibitors appeared both effective in counteracting Cx43 degradation. Also, brefeldin A caused internalization of Cx43 gap junction, as a step preceding degradation. Strikingly, proteasomal inhibitors could largely restore the presence of $\mathrm{Cx} 43$ in gap junctional plaques at appositional membranes in brefeldin A-treated cells, while lysosomal inhibitors were much less effective. In the latter, $\mathrm{Cx} 43$ gap junctions mainly appeared in intracellular vesicles. Different studies provided evidence for endolysosomal Cx43 degradation (reviewed in [28]). Plasmalemmal Cx43 gap junctions internalized via the endocytic pathway and subsequently fused with lysosomal structures (Fig. 3). As discussed elsewhere [29], Cx43 internalization depended on the presence of clathrin, clathrin-adaptor proteins (including AP-2 and Dab2) and dynamin 2 and on dynamin GTPase activity. Also, the Cx43-interacting protein of $85 \mathrm{kDa}$, CIP85, an ubiquitously expressed Rab GTPaseactivating protein, emerged as a critical factor for $\mathrm{Cx} 43$ internalization and lysosomal degradation [67]. CIP85 colocalized with $\mathrm{Cx} 43$ at the cell surface by means of a direct interaction between CIP85 and Cx43, involving the SH3 domain and the proline-rich region $\mathrm{P}^{253} \mathrm{LSP}^{256}$, respectively. Overexpression of CIP85, but not CIP85 lacking its SH3 domain, increased Cx43 turnover likely by recruiting clathrin and subsequently enhancing Cx43 internalization as gap junctions from the plasma membrane [67]. Strikingly, lysosomal inhibitors, such as $\mathrm{NH}_{4} \mathrm{Cl}$ or leupeptin, but not proteasomal inhibitors, such as MG132, prevented the increased turnover of $\mathrm{Cx} 43$ by CIP85 overexpression 


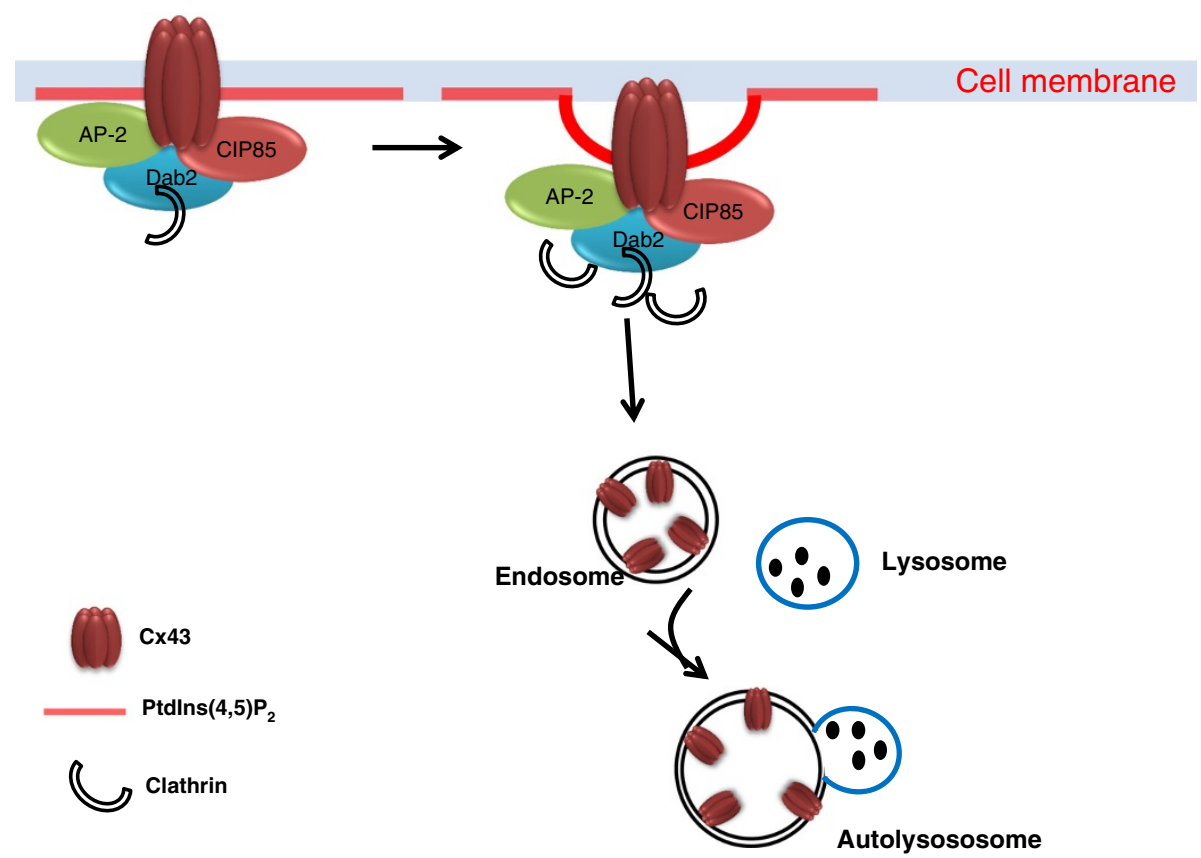

Fig. 3 Endolysosomal degradation: CIP85 interacts with Cx43 via SH3 domain at plasma membrane. Initiation of clathrin-mediated endocytosis starts at Ptdlns $(4,5) \mathrm{P}_{2}$-rich sites in the plasma membrane where the AP2 adaptor complex associates and recruits further accessory proteins. AP2 complexes connect the cargo membrane protein to clathrin coat. GTPase dynamin is necessary for movement of the vesicle and cargo into the cell. Internalized Cx43 are degraded via lysosomal degradation

[68]. Further studies showed the accumulation of connexins in lysosomes in cells exposed to lysosomal inhibitors, preventing their degradation and correlating with an increased appearance of $\mathrm{Cx} 43$ at the cell surface in such conditions [69].

\section{Autophagy: an emerging connexin-degradation pathway}

Besides the endosomal/lysosomal pathway, in recent years, autophagy emerged as an important connexin-degradation pathway. This is supported by electron microscopic observations made about 30 years ago showing the presence of gap junctions in autophagic structures, the typical double membrane vesicles containing cellular material [52]. However, only recently, mechanistic insights in the role of autophagy for connexin turnover have been obtained.

\section{Basic molecular mechanisms underlying connexin degradation by autophagy}

The first direct evidence for a role of autophagy in connexin degradation was provided by the work of Beyer and his team [70]. Nutrient starvation, a potent inducer of the canonical mTOR-controlled autophagy pathway, triggered a rapid decline in the protein levels of wild-type Cx50, ectopically expressed in HeLa cells, and of wild-type Cx43, endogenously expressed in NRK cells. Nutrient starvation periods of just $2 \mathrm{~h}$ already impacted $\mathrm{Cx} 43$ - and Cx50-protein levels. This corresponded with a marked decline in Cx43 and Cx50 levels at the plasma membrane and in perinuclear regions and a prominent increase in cytosolic LC3-positive autophagosomal punctae that stained positive for $\mathrm{Cx} 50$. About $1 / 3$ of the intracellular Cx50 co-localized with LC3 in cells undergoing starvation for $4 \mathrm{~h}$. Also, p62, another autophagic marker, could be detected in punctae that co-localized with intracellular, but not plasmalemmal, Cx50 or Cx43. Importantly, intracellular connexin gap junctions appeared in intracellular double membrane vesicles that were in close proximity of the endoplasmic reticulum, a hall-mark of autophagosome formation and autophagy. Basal autophagy appeared to contribute to the normal turn-over of $\mathrm{Cx} 50$ and $\mathrm{Cx} 43$ proteins, since chloroquine, a lysosomal inhibitor, caused an increase of about $30 \%$ in basal Cx50-protein levels in transfected HeLa cells and of more than $100 \%$ in basal, endogenous Cx43-protein levels in NRK cells, both grown in normal, nutrient-rich medium conditions. In these cell systems, chloroquine largely prevented the starvationinduced decline in Cx50- and Cx43-protein levels. These observations correlated with the co-localization of LC3 with both $\mathrm{Cx} 50$ and $\mathrm{Cx} 43$ under normal growth conditions, suggesting connexin turnover by basal autophagy and an increased co-localization during starvation periods (in the presence of chloroquine to prevent connexin degradation). Also depleting cells of Atg (autophagy-related) proteins, essential for autophagic flux, impacted connexin-protein levels. Knocking down Atg5 caused an 
increase of about $50 \%$ in the basal Cx50-protein levels in non-starved HeLa cells and largely prevented the starvation-induced decline in Cx50-protein levels in starved HeLa cells. Similar results were obtained for $\mathrm{Cx} 43$ in MEF cells, in which Atg5-knockout MEF did not display any decline in Cx43-protein levels upon starvation. This study also implicated autophagy as an important degradation pathway for mutant $\mathrm{Cx} 50$ proteins, like $\mathrm{C} \times 50^{\mathrm{P} 88 \mathrm{~S}}$ associated with cataract. In fluorescent microscopy experiments, cytoplasmic accumulation of $\mathrm{Cx} 50^{\mathrm{P} 88 \mathrm{~S}}$ co-localized with the endogenous autophagosomal markers LC3 and p62, and with the lysosomal markers LAMP1. Consistently, starvation caused a major decline in the Cx50P88Sprotein levels compared to non-starved conditions. The co-localization of p62 with Cx43 and Cx50 might imply a role for p62 in targeting connexins to the autophagic machinery for degradation, given p62's role as a linker protein between ubiquitinated proteins and LC3.

In subsequent work by Cuervo and co-workers [71], molecular determinants controlling $\mathrm{Cx} 43$ degradation by autophagy were elucidated. In this study, it was shown that several endogenously expressed connexins, Cx26, Cx32 and Cx43, in the liver were present in autophagic vesicles (autophagosomes and autophagolysosomes) and co-fractionated with LC3. Connexin accumulation in the autophagic vesicles became more pronounced in liver samples starved for $6 \mathrm{~h}$ and in cultured cells from which serum was removed. Depletion of essential autophagy proteins in cells by Atg7 knockdown or Atg5 knockout prevented the degradation of connexins in response to serum removal. Similar effects were obtained using 3methyladenine, a PI3K inhibitor that inhibits autophagy by suppressing autophagosome formation. Using photoswitchable Dendra-fused connexins to track de novo synthesized proteins as red fluorescent proteins, it was observed that serum-starvation caused the rapid degradation of Cx26, Cx32 and Cx43. However, in contrast to Cx26 and Cx32, Cx43 could be completely rescued by Atg7 knockdown, implying different roles for autophagy in the degradation of different connexin isoforms. Consistent with these findings, serum removal caused Cx43 relocalization from the plasma membrane to autophagosomes. The presence of Cx43 in these LC3/ p62-positive vesicles was enhanced upon treatment with lysosomal inhibitors. In serum removal conditions, the degradation of $\mathrm{Cx} 43$ appeared to be mediated via the lysosomes but not the proteasome, since proteasomal inhibitors (MG132 or lactacystin) did not prevent the decline in Cx43-protein levels. Further cell surface biotinylation and confocal microscopy experiments revealed that mainly $\mathrm{Cx} 43$ gap junctions are rapidly degraded by autophagy in conditions of nutrient starvation. As a consequence, Cx43 remained present in the plasma membrane of starved cells treated with 3-MA or in which Atg5 or Atg7 was ablated. These findings were supported by in vivo evidence in liver-specific ATG7-knockout mice, displaying increased $\mathrm{Cx} 43$ levels and enhanced appearance of $\mathrm{Cx} 43$ at the plasma membrane. These molecular findings were also supported by evidence obtained at the functional level. Intercellular dye spreading, a measure for gap junctional coupling, was markedly declined upon nutrient starvation, while this decline could be alleviated upon chemical or genetic inhibition of autophagy. In addition, a link between internalization and autophagy was established. Indeed, lindane caused $\mathrm{Cx} 43$ internalization and degradation involving a time-dependent and autophagy-dependent redistribution of Cx43 from the plasma membrane to late endosomal/ lysosomal vesicles identified by LAMP-1. The requirement of $\mathrm{Cx} 43$ internalization for its autophagic degradation was further elegantly illustrated by the use of the endocytosisdeficient $\mathrm{Cx} 43^{\mathrm{Y} 286 \mathrm{~A}}$ mutant. Interestingly, in contrast to wild-type GFP-Cx43, GFP-C $x 43{ }^{\mathrm{Y} 286 \mathrm{~A}}$ persisted at gap junctions in the plasma membrane in starved cells. The internalization and autophagic degradation of $\mathrm{Cx} 43$ appeared to be dependent on ubiquitination of Cx43 by Nedd4 (Fig. 4a) and the further recruitment of the endocytic protein epidermal growth factor receptor substrate 15 (Eps15). Nedd4, an ubiquitin ligase enzyme, was previously implicated in binding the C-terminus of $\mathrm{Cx} 43$ and mediating Cx43 ubiquitination [72-74]. Eps15, an endocytic adaptor protein containing ubiquitin-binding domain, was previously identified to interact with ubiquitinated $\mathrm{Cx} 43$ and promote its internalization [74]. Serum starvation induced Nedd4-dependent ubiquitination of $\mathrm{Cx} 43$, but not of the $\mathrm{Cx} 43^{\mathrm{Y} 286 \mathrm{~A}}$ mutant, before its accumulation in autophagosomes [71]. Cx43 expressed in Nedd4-deficient cells was resistant to degradation by nutrient starvation. These findings were corroborated by showing that ectopically expressed $\mathrm{Cx} 43$, but not $\mathrm{Cx} 43^{\mathrm{Y} 286 \mathrm{~A}}$, fused to a single ubiquitin molecule was rapidly degraded in an autophagydependent manner in response to nutrient starvation. It was here confirmed that p62 served as cargo-recognition factor, forming a bridge between ubiquitinated $\mathrm{Cx} 43$ and LC3. Cx43-p62 interaction was enhanced during starvation, but was strongly diminished in cells lacking Nedd4. Furthermore, a critical role for Eps15 was identified in the early steps of Cx43 degradation.Cx43-Eps15 interaction was enhanced upon starvation, directing $\mathrm{Cx} 43$ for autophagic degradation. In cells lacking Eps15, Cx43 persisted at gap junctions in the plasma membrane upon nutrient starvation. Cx43-Eps15 interaction did not require autophagy, since cells lacking Atg5 or Atg7 or treated with 3-MA even displayed higher levels of Cx43-Eps15-complex formation. However, ubiquitination of $\mathrm{Cx} 43$ was critical for Eps15 interaction, since $\mathrm{Cx} 43^{\mathrm{Y} 286 \mathrm{~A}}$ and $\mathrm{Cx} 43$ expressed in Nedd4-deficient cells failed to recruit Eps15 in response to serum starvation. Excitingly, in this study [71], Eps15 was also identified as a novel autophagy cargo recognition 


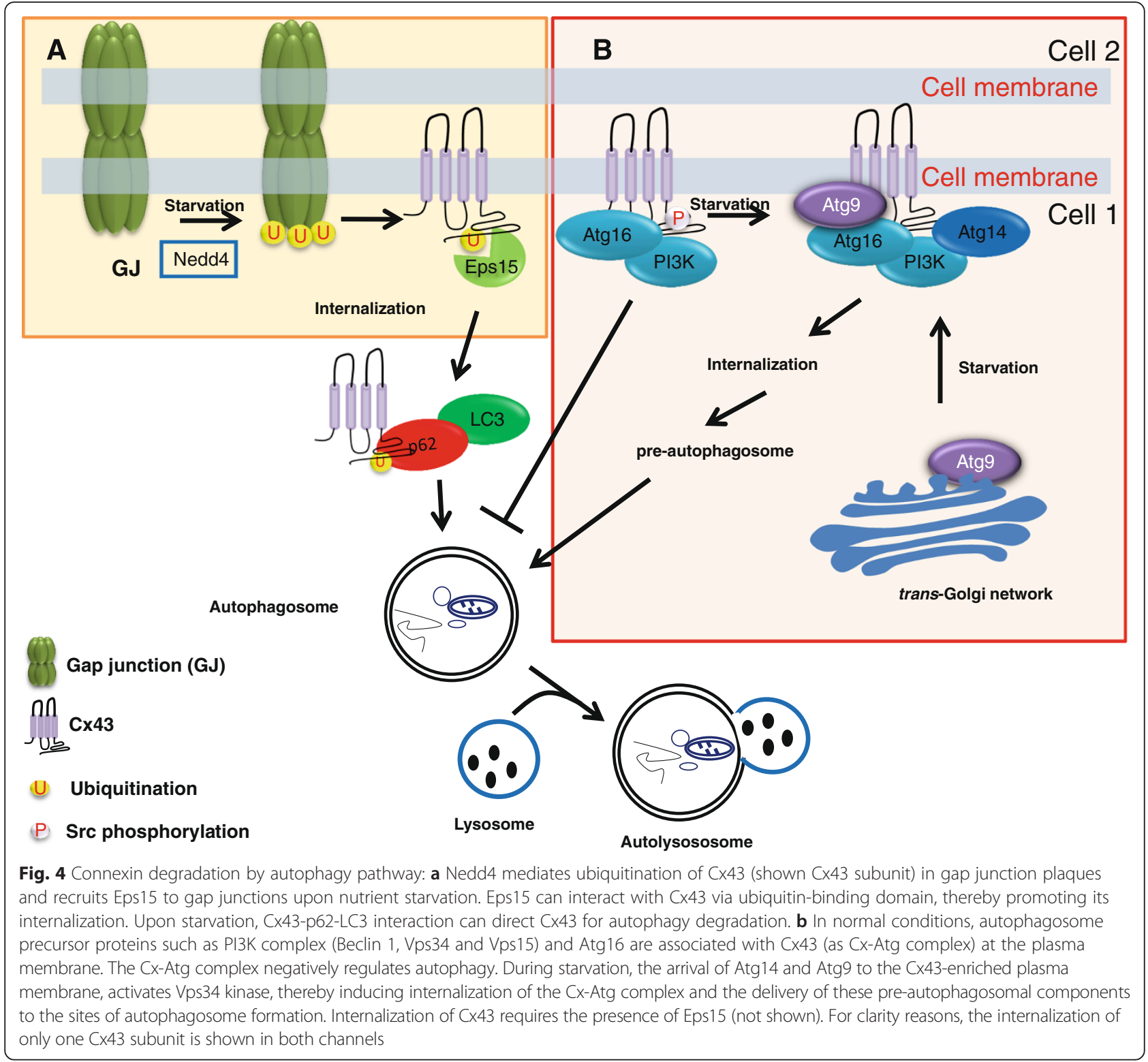

molecule, given its ability to interact with LC3 in LC3immunoprecipitation assays and its ability to recruit LC3 and $\mathrm{Cx} 43$ in Eps15-immunoprecipitation assays. In any case, these data revealed autophagy as a major turnover pathway for $\mathrm{Cx} 43$ via a mechanism that involves Nedd4-dependent ubiquitination, recruitment of Eps15 and associations with the autophagic machinery, thereby facilitating $\mathrm{Cx} 43$ gap junction internalization and autophagic degradation via the lysosomes.

A detailed ultrastructural, microscopy-based study also revealed autophagy as a major clearance/degradation pathway for internalized annular gap junctions from the cytoplasm [75]. Internalized annular gap junctions appeared to co-localize with autophagosomal cargo, sequestration and degradation markers, like p62, RAB-7 and LC3.
Double-membrane phagophore formation could be observed around annular gap junctions, eventually resulting in lysosomal degradation. Interfering with autophagy using pharmacological agents or by knocking down essential autophagy or cargo proteins increased total Cx43-protein levels and augmented the number of Cx43-containing annular gap junctions. It was postulated that these annular gap junctions resemble large and complex protein/vesicular structures (e.g. like protein aggregates, multi-protein complexes, damaged organelles and pathogens) that are typically removed from the cytoplasm via autophagy rather than via the proteasome [75]. However, a subset of the annular gap junctions could be directed to the lysosomes via the endosomal system, as has been observed for hyperphosphorylated and hyperubiquitinated $\mathrm{Cx} 43$ in response to 
chemical PKC hyperactivation [76]. Shuttling of ubiquitinated $\mathrm{Cx} 43$ from endosomes to lysosomes appears to be dependent on two ubiquitin-binding proteins, namely Hrs (hepatocyte growth factor-regulated tyrosine kinase substrate; also known as Hgs) and Tsg101 (tumor susceptibility gene 101) [77]. Another recent ultrastructural study revealed that annular gap junctions could be recycled to the plasma membrane or degraded via three pathways, including endo-lysososomal pathways, autophagosomal pathways and a direct engulfment by lysosomes [78].

\section{Connexin degradation by autophagy in different cellular and physiological systems and pathophysiological conditions}

An increasing number of studies report an emerging role for autophagy as the turnover pathway of connexins in pathophysiological conditions and diseases, including ischemic insults and cancers.

\section{Low $\mathrm{pH}$ in pancreatic acinar cells}

Besides starvation, low $\mathrm{pH}$, a condition known to uncouple connexin gap junctions in heart [79], has been implicated in the degradation of $\mathrm{Cx} 32$ gap junctions present in pancreatic acinar cells [80]. In particular, low $\mathrm{pH}$ in combination with cerulein, which triggers $\mathrm{IP}_{3}$-induced $\mathrm{Ca}^{2+}$ oscillations synchronized by gap junctions, caused a striking decline in Cx32-protein levels and Cx32 gap junction-mediated coupling of acinar cells. In these conditions, Cx32 gap junctions were lost and rapidly turned over, correlating with a punctate intracellular localization. The decline in Cx32-protein levels by the low $\mathrm{pH} /$ cerulean treatment could be prevented by lysosomal inhibitors and by the PI3K/autophagy inhibitor 3-MA. However, also proteasomal degradation pathways appeared to contribute to $\mathrm{Cx} 32$ degradation in this system. In another study, cadmium-induced toxicity in BRL 3A rat liver cells was linked to an increase in autophagic markers and an upregulation of essential autophagy proteins Atg5, Atg7 and Beclin 1. This coincided with a decrease in Cx43-protein levels and gap junctional coupling, which could be counteracted by lysosomal inhibitors and aggravated by the autophagy-inducer rapamycin.

\section{Heart failure and ischemia in the heart}

A first study focusing on normal and failing heart was able to link autophagic markers to lateralized and subsequently internalized Cx43 gap junctions in cardiomyocytes [81]. In normal hearts, $\mathrm{Cx} 43$ gap junctions appear at the intercalated disc region of the cardiomyocyte plasma membrane to properly propagate and spread electrical signals coordinating heart contractions. In failing hearts, $\mathrm{Cx} 43$ gap junctions relocalize to lateral cell membranes. In these failing hearts, $\mathrm{Cx} 43$ gap junctions became internalized and appeared in multilamellar membrane structures. The membranes appeared to contain buoyant, cholesterol and sphingolipid-rich membrane domains (referred to as lipid raft or LR membrane domains), in which a subset of the Cx43 gap junction population can be accumulating. Interestingly, in failing hearts, the total $\mathrm{Cx} 43$ protein levels declined correlating with an increased accumulation of the Cx43 protein in these LR membrane domains compared to the Cx43 levels in LR membrane domains from normal hearts. These structures also resembled the properties of autophagosomes and accumulated the lipidated protein LC3-II, which too became upregulated in failing hearts. As such, the LR fractions contained both Cx43 and LC3 protein. Interestingly, Cx43 and GFP-LC3 co-localized in intracellular punctae resembling autophagosomes in HeLa cells and in neonatal rat ventricular cardiomyocytes. However, this study did not show whether autophagy or its increased flux was responsible for the turnover and degradation of the $\mathrm{Cx} 43$ gap junctions.

Further work on the cardiac system focused on the role of autophagy in degrading Cx43 upon ischemia and ische$\mathrm{mia} /$ reperfusion. Ischemia/reperfusion has been associated with excessive autophagy induction in different physiological systems like the heart [82], liver [83] and kidneys [84], resulting in detrimental effects like autophagydependent cell death or autosis [85]. In the cardiomyocyte cell line HL-1, ischemia diminished total Cx43-protein levels and plasmalemmal Cx43 levels, including hemichannels and gap junctions [86]. This decline in Cx43 could be partially rescued by lysosomal inhibitor Bafilomycin A, implying ischemia-induced $\mathrm{Cx} 43$ degradation by autophagy in HL-1 cells. These observations correlated with an increased appearance of autophagosomes, LC3-II accumulation, GFP-LC3-punctae formation and Cx43LC3 co-localization in HL-1 during ischemia. These findings were also observed in organotypic heart slices and in Langendorff heart preparations. Functionally, ischemia in HL-1 reduced intercellular coupling via gap junctions, which could be rescued by the autophagy inhibitor 3-MA. Consistent with previous studies, a "proximal" role for Eps15 was found for the internalization of $\mathrm{Cx} 43$ that became ubiquitinated during ischemia and a more "distal" role for p62 for the targeting of the internalized, ubiquitinated $\mathrm{Cx} 43$ to the autophagic machinery. Unexpectedly, while Nedd4 controlled ubiquitination of Cx43 and impacted basal Cx43 level in HL-1 cells, ischemia-induced ubiquitination and degradation of $\mathrm{Cx} 43$ was not altered in HL-1 cells in which Nedd4 was knocked down. This suggests that other E3 ubiquitin ligases may be involved in ubiquitination of $\mathrm{Cx} 43$ during ischemia. Also ischemia/reperfusion caused $\mathrm{Cx} 43$ degradation in a more excessive manner than ischemia alone. Cx43 degradation too relied on autophagy, although 3-MA added only during reperfusion could not prevent $\mathrm{Cx} 43$ degradation, implying an important role for Cx43-containing autophagosomes that have been accumulating during the ischemia period. 
Interestingly, AMP-activated kinase (AMPK) and Beclin 1 appeared to play different key roles in the Cx43 degradation upon ischemia versus ischemia reperfusion. Early on during ischemia, AMPK is robustly activated, implying a marked decline in cellular ATP levels. Chemical inhibition of AMPK could partially prevent ischemia-induced $\mathrm{Cx} 43$ degradation during these early periods of ischemia. Extended periods of ischemia led to a decline in AMPK activity and a failure of the AMPK inhibitor to stabilize Cx43. During these extended periods, Beclin 1 appeared important, since siRNA against Beclin 1 could prevent $\mathrm{Cx} 43$ degradation during the longer ischemia periods. During ischemia/reperfusion, only Beclin 1 siRNA but not AMPK inhibition was effective in preventing $\mathrm{Cx} 43$ degradation. Thus, these data imply different molecular autophagy key players become activated during the different periods of ischemia and ischemia/reperfusion, ultimately controlling Cx43 degradation. Very interestingly, a recent study aiming to document the proteomic changes associated with the susceptibility of neonatal versus adult murine hearts to ischemia/reperfusion reported an increase in Cx43 levels but a decrease in Beclin 1 levels upon maturation [87].

\section{Oncogenesis in different tumors}

Both altered autophagy $[88,89]$ and altered connexin expression [90-92] have been implicated in oncogenesis in a variety of tumors. In particular, in a variety of tumors connexin gap junctions appear to be downregulated [93], yet the contribution of autophagy in oncogenic connexin downregulation is definitely not clear. Nevertheless, a number of studies appear to suggest the involvement of autophagy in connexin turnover in tumors.

For instance, in non-small cell lung cancer cells (NSCLC), autophagy is responsible for the rapid degradation and downregulation of the Cx31.1. isoform. In H1299, a NSCLC cell line, Cx31.1 overexpression resulted in an intracellular localization of the protein, consistent with the very rapid turn-over of Cx31.1 in these cells. The rapid turnover of Cx31.1 could only be partially prevented by proteasomal inhibitors. Moreover, autophagy-inducing conditions like starvation and brefeldinA further increased the rapid decline in Cx31.1 that was only mildly impacted by proteasomal inhibitors. In contrast, knockdown of Atg5 prominently protected $\mathrm{Cx} 31.1$ against starvation-induced degradation. In these cells, Cx31.1 appeared in intracellular punctae that co-localized with the autophagic marker LC3 upon starvation. An unbiased mass spectrometry analysis of GFP-Cx31.1 immunoprecipitated samples revealed clathrin as a potential Cx31.1-binding partner, confirmed in direct co-immunoprecipitation assays. Cx31.1 and clathrin co-localized in cells, including in intracellular punctae that became more pronounced in starved cells. Knockdown of clathrin appeared to augment basal Cx31.1 levels and prevented the starvation-induced decrease of $\mathrm{Cx} 31.1$ in these cells. Hence, this study shows that autophagy may contribute to the degradation of different connexin isoforms in cancer cells, although the impact of restoring Cx31.1 expression through autophagy inhibition on the oncogenic properties of these tumors ought to be further characterized.

A further role for altered connexin presence in tumors linked to autophagy has been observed in keratocystic odontogenic tumors [94]. In these tumor samples, Cx43 and Cx32 levels were significantly downregulated compared to normal oral mucosa samples. The Cx43 and Cx32 levels negatively correlated with the expression of the autophagy markers LC3 and p62. This may imply that excessive autophagy and upregulation of autophagy markers linked to both $\mathrm{Cx} 43$ and $\mathrm{Cx} 32$ degradation could contribute to the downregulation of $\mathrm{Cx} 43$ and Cx32 in these tumors. Thus, inhibiting autophagy may have a tumor suppressive potential in these patients by restoring normal $\mathrm{Cx} 43$ and $\mathrm{Cx} 32$ levels.

Connexin degradation by autophagy also has been implicated as an escape mechanism of tumor cells for immune surveillance by natural killer cells [95]. In particular, hypoxic stress, occurring in the tumor micro-environment, appears to be involved in escaping immune surveillance, including a suppressed susceptibility of tumor cell lysis by natural killer cells [96]. While hypoxic stress increased the total Cx43-protein levels in a HIF1 $\alpha$-driven manner in melanoma cells, the presence of $\mathrm{Cx} 43$ gap junctions at the immunological synapse between melanoma cells and natural killer cells was strongly diminished [95]. The decline of Cx43 gap junctions at the immunological sequence was dependent on the increased autophagic flux occurring during hypoxia. Indeed, the presence of $\mathrm{Cx} 43$ at the immunological synapse could be restored by inhibiting lysosomes or knocking down Atg5. Importantly, inhibiting autophagy and thus preventing the subsequent degradation of $\mathrm{Cx} 43$ at the immunological synapse was very effective in restoring the susceptibility of hypoxic melanoma cells towards natural killer cell-mediated lysis. These findings were corroborated by the use of the endocytic $\mathrm{Cx} 43^{\mathrm{Y} 286 \mathrm{~A}}$ mutant, which remained present at the immunological synapse during hypoxic stress and also restored the susceptibility of tumor cells towards lysis by natural killer cells in hypoxic conditions. Thus, this study suggests that inhibition of autophagy may serve as a strategy to render tumors more vulnerable to attacks by the immune system (e.g. through lysis by natural killer cells) by restoring the presence of connexin at immunological synapses.

\section{Relevance of connexin degradation by autophagy}

The cellular and physiological relevance of connexin degradation by autophagy, in particular in response to stress conditions like nutrient starvation, remains to be further explored. In general, it is proposed that autophagy activation as an initial response to stress serves as a cell survival 
pathway while evading cell death. However, excessive or prolonged autophagy will lead to and/or contribute to cell death. Also, autosis, a new form of cell death associated with high levels of autophagy, has been described [85]. Furthermore, there are several mechanistic links between autophagy and several cell death processes [85, 97]. For instance, anti-apoptotic Bcl-2 proteins can bind Beclin 1, thereby preventing its pro-autophagic function and thus co-regulating apoptosis and autophagy [98]. Also, receptorinteracting protein kinase-1 (RIPK1), a signaling node in the control of apoptosis and necroptosis in response to extrinsic death factors, suppresses basal autophagy by promoting ERK-dependent phosphorylation of TFEB, thereby suppressing its transcriptional activity that is involved in the expression of genes with functions in autophagy and lysosomal biogenesis $[99,100]$. Moreover, several proteins with pro-death functions have been shown to be degraded by autophagy [85]. For instance, FDA-approved inhibitors of mTOR decrease RIPK1 and RIPK3 levels in human renal cell carcinoma cells by activating autophagy, which underlies their resistance to these mTOR inhibitors [101]. Inhibition of autophagy using the lysosomal inhibitor chloroquine leads to RIPK1/RIPK3 stabilization in mTOR inhibitor-treated cells, thereby promoting necroptotic cell death in these cells. Autophagy also impacts the phosphatase FAP1 (Fas-associated phosphatase 1), which counteracts Fas/CD95-induced apoptotic cell death [102]. Cells with increased autophagy flux display reduced levels of FAP1, thereby sensitizing these cells to apoptosis elicited by Fas/CD95 signaling. Finally, also activated caspase 8 has been reported to be sequestered into autophagosomes and degraded in the lysosomes, thereby rendering Baxdeficient Hct116 cells resistant to TRAIL-induced apoptosis [103]. Inhibiting autophagy restored TRAIL-induced caspase 8-dependent apoptotic responses in these cells.

Importantly, connexin gap junctions too have been linked to cell death processes and were shown to be responsible for the spreading of cell death factors between neighboring cells involving the diffusion of $\mathrm{IP}_{3}$ as a critical factor $[104,105]$. Connexin hemichannels may mediate the loss of essential survival factors and release of ATP, glutamate and prostaglandins as factors that participate in cell-death spreading through paracrine signaling [106]. Also, $\mathrm{Cx} 43$ gap junctions and ATP release contribute in vivo to the spreading of radiation-induced damage from the irradiated region (e.g. containing tumor cells) to other neighboring unexposed regions (e.g. healthy tissues) [107]. In that sense, the increased turnover of connexin proteins as pro-death signaling complexes by autophagy could be a manner to prevent cell death or cell death spreading during these early adaptive responses. Further work using strategies that favor the stabilization of connexin proteins during autophagy induction treatments and subsequently assess the impact on cell viability, susceptibility to cell death stimuli and cell death spreading should provide further insights in this process. In addition, Cx43 is also present in intracellular organelles, including the mitochondria, and can also control cell survival. Yet, their susceptibility towards stress conditions and autophagy degradation has not yet been studied. For a detailed discussion of the role of connexins as gap junctions and hemichannels or their channel-independent functions in controlling cell death and survival, we wish to refer to different reviews dealing with these topics $[34,36,106]$.

At the physiological level, it will be interesting to understand how autophagy impacts connexin functions as gap junctions and hemichannels and connexin-mediated signaling processes in native tissues like brain, including the astroglial network, heart and bone. In particular, the use of tissue-specific knockouts for autophagy-dependent genes will be instrumental to unravel the physiological role of autophagy-dependent regulation of connexins, connexin-mediated signaling and connexin-controlled processes in vivo. Also, autophagy has been shown to decrease during ageing, to be impaired in different pathologies including neurodegenerative diseases and to play an anti-inflammatory role $[108,109]$. Now, connexins too have been implicated in these processes with severe alterations in function and expression in several disease conditions $[43,110,111]$. For instance, the excessive opening of astroglial hemichannels has been implicated in response to inflammatory cytokines and amyloid $\beta$, leading to neuronal cell death [112-114]. Hence, alterations in autophagy might impact the surface level of connexins in gap junctions and hemichannels in these cell types and thus the pathophysiological outcome.

\section{Connexins: an emerging negative regulator of autophagic flux}

While autophagy impacts connexin levels, it is also clear that connexins by themselves can suppress the autophagy process by recruiting pre-autophagosomal Atg proteins and PI3K components (Fig. 4b), as recently reported in a seminal paper by Cuervo and co-workers [115]. Cx43 could co-localize and associate with Atg16, a marker for preautophagosomal structures. The co-localization of $\mathrm{Cx} 43$ with Atg16 was not altered in cells undergoing nutrient starvation, in cells exposed with 3-MA or in cells lacking Atg15. The Cx43-Atg16 complex appeared prior to autophagy activation, since it did not contain Atg5. Importantly, mouse osteoblasts obtained from wild-type versus Cx43knockout mice displayed altered autophagy. In the absence of $\mathrm{Cx} 43$, autophagic flux was enhanced with an increase in the number of autophagic vesicles and of steady state LC3II levels. The inhibition of autophagy by $\mathrm{Cx} 43$ was independent of its ability to form functional gap junctions, since chemical inhibition of $\mathrm{Cx} 43$ gap junctions did not increase autophagic flux, while GFP-Cx43, a fusion protein that is 
located at the plasma membrane but that fails to form functional gap junctions, was fully capable of inhibiting autophagy. Interestingly, a C-terminally truncated $\mathrm{Cx} 43$ protein at position 258 too could repress autophagy correlating with its ability to interact with Atg16, while Cx43 truncated at position 245 failed to repress autophagy and to interact with Atg16. The 245-258 region also contains a Srcphosphorylation site. Inhibiting Src activity robustly increased autophagy in Cx43-expressing but not in Cx43knockout cells, indicating a role for Src-dependent phosphorylation of $\mathrm{Cx} 43$ in suppressing autophagy. Besides Atg16, Cx43 also recruited different components of the class III PI3K complex. Different members of this initiation complex, Vps34, Beclin 1 and Vps15, were found to interact with $\mathrm{Cx} 43$ in normal, starved or rapamycin-treated conditions and independent on the expression of Atg5 or Atg16. Also other connexin isoforms appeared to negatively impact autophagic flux, indicating that many connexin-family members might serve as general autophagy regulators. Knockdown of Cx26 or Cx32 in MEF cells resulted in increased autophagy, coinciding with their ability to bind and recruit Atg16. Agents that promoted acute internalization of Cx43 also increased autophagic flux in a Cx43-dependent manner. Indeed, tamoxifen and lindane increased autophagy in Cx43-expressing cells, but not in Cx43-knockout cells, which displayed already high autophagy in basal conditions. The internalization of $\mathrm{Cx} 43$ also resulted in a decrease in Cx43-Atg16-complex formation, while Atg16-positive pre-autophagic compartments became more prevalent. Internalization of $\mathrm{Cx} 43$ appeared to be dependent on the recruitment of Atg9 and Atg14 towards Cx43-enriched plasma membrane regions. Upon starvation, several Atg9 (multimembrane-spanning protein) vesicles are redistributed from trans-Golgi network and interact with phagophores during early steps of autophagosome formation [116]. Both Atg9 and Atg14 must be present in these regions in a spatiotemporal manner before Cx43 gap junctions can be internalized and degraded by autophagy. Interestingly, the presence of Atg9 and Atg14 at the plasma membrane and their interaction with $\mathrm{Cx} 43$ was prominently increased upon conditions of serum starvation, explaining the increased Cx43 internalization during nutrient starvation. It is interesting to note that other channels have been implicated as regulators of the autophagy process by scaffolding/recruiting essential autophagy proteins. For instance, the inositol 1,4,5-trisphosphate receptor $\left(\mathrm{IP}_{3} \mathrm{R}\right)$, an intracellular $\mathrm{Ca}^{2+}$-release channel located at the endoplasmic reticulum, has been shown to recruit Beclin 1, thereby limiting its availability for the PI3K initiation complex and thus suppressing autophagy [117-119]. However, other studies proposed a stimulatory role for $\mathrm{IP}_{3}$ Rs in autophagy by recruiting Beclin 1 , sensitizing the $\mathrm{IP}_{3} \mathrm{R}$ channel to its agonist $\mathrm{IP}_{3}$ and promoting intracellular $\mathrm{Ca}^{2+}$-signaling events that are essential to upregulate autophagic flux in response to nutrient starvation [120-123].

Further studies have implicated that connexins could regulate the autophagy pathway. In hippocampal tissues obtained from rats exposed to traumatic brain injuries, astrocytic phosphorylated Cx43 levels increased, coinciding with an increase in the autophagic marker LC3-II in the neurons [124]. Carbenoxolone, a Cx43 gap junction/ hemichannel inhibitor, prevented the increase in phosphorylated $\mathrm{Cx} 43$ caused by traumatic brain injury and also suppressed the increase in LC3-II levels. These experiments therefore suggested a link between the appearance of phosphorylated Cx43 in astrocytes and autophagy induction in neurons as a potential mechanism for brain injuries. This was further underpinned by in vivo experiments, in which both carbenoxolone and 3-MA could alleviate the memory deficits induced by traumatic brain injuries in an assay testing for spatial memory [125]. This correlated with a partial reversal of the loss of long-term potentiation in rat hippocampal slices induced by traumatic brain injury. Thus, both increased phosphorylated $\mathrm{Cx} 43$ and autophagy appeared to negatively impact brain function in this setup. At the molecular level, traumatic brain injury reduced the expression of the glutamate transporter GLT-1 and increased the expression of the ionotropic purinergic receptor P2X7R. Collectively, suppressing $\mathrm{Cx} 43$ phosphorylation by carbenoxolone, inhibiting P2X7R using oxATP or activating the GLT-1 transporter were able to counteract traumatic brain injury-induced Beclin 1 upregulation. Furthermore, phosphorylated Cx43 and the upregulation of the P2X7R were also able to prevent the injury-induced decline in GLT-1 levels. Collectively, these data imply a cascade in which the accumulation of phosphorylated $\mathrm{Cx} 43$ in astrocytes during brain injury leads to an upregulation of P2X7R, augmenting ATP release and ATP-induced signaling processes that result in a decrease in GLT-1 and excessive activation of the autophagic pathway via a marked upregulation of Beclin 1. This "toxic" signaling cascade appears to negatively impact brain functions after traumatic injury, since interfering with either Cx43 or autophagy is able to partially restore neuronal functions. However, the molecular mechanisms by which elevated levels of phosphorylated Cx43 in astrocytes upregulate autophagy in neurons require further studies.

\section{Conclusions}

There is increasing evidence that autophagy and connexins are interrelated. On the one hand, autophagy is emerging as an important connexin-degradation pathway not only under basal and normal growth conditions and wellestablished autophagy-inducing conditions like nutrient starvation but also in a variety of pathological conditions. Autophagic degradation of $\mathrm{Cx} 43$ critically depends on Cx43 internalization, thereby requiring ubiquitination (e.g. 
by Nedd4), ubiquitin-binding proteins (e.g. Eps15), interactions with autophagic cargo proteins (e.g. p62), autophagosome markers (e.g. LC3) and other autophagy proteins that act early on in the process (e.g. Atg9 and Atg14). Furthermore, the degradation by autophagy is not limited to Cx43 but seems to contribute to the rapid turnover of many connexin isoforms, in particular during conditions of autophagy activation like nutrient starvation. In addition, autophagy is also important for the rapid turnover of mutant connexins associated with severe human diseases and altered autophagy in pathophysiological conditions can lead to impaired or enhanced connexin degradation. On the other hand, connexins are also emerging as novel negative regulators of the autophagy process by recruiting essential autophagy proteins to the plasma membrane, including Atg16 and PI3K-complex components like Vps34, Beclin 1 and Vps15 that act in the earlier steps of the autophagy process. As such, connexins can be limiting their availability for inducing autophagy upstream of autophagosome formation. As highlighted by Cuervo and co-workers [71, 115], the important interplay between connexins and autophagy is underscored by the fact that many connexin-associated diseases have been linked with altered autophagy, including cardiovascular diseases, ocular diseases, diabetes and cancer.

\section{Competing interests}

The authors declare that they have no competing interests.

\section{Authors' contributions}

GB designed the conceptual organization of the manuscript. JY, JDPC and GB participated in drafting and writing the manuscript and making the figures. LL and $\mathrm{CDH}$ critically corrected and amended the manuscript and its figures. All authors read and approved the final manuscript.

\section{Acknowledgements}

The work has been supported by Concerted Actions of the K.U. Leuven (GOA/09/012), the Research Foundation - Flanders (F.W.O.; grant G.0298.11 to $L L$ and GB), Interuniversity Attraction Poles Program (Belgian Science Policy; P6/28 and P7/13 to G.B, and P6/31 and P7/10 to L.L.) and a "Krediet aan Navorser" grant of the FWO (15117.14 N to CDH and GB). We thank all group members for helpful discussions.

\section{Declarations}

The publication charges for this article were funded by a grant obtained from the Research Foundation - Flanders (FWO grant 15117.14 N to CDH and $\mathrm{GB})$.

This article has been published as part of BMC Cell Biology Volume 17 Supplement 1, 2016: Proceedings of the International Gap Junction Conference 2015. The full contents of the supplement are available online at http://bmccellbiol.biomedcentral.com/articles/supplements/volume-17supplement-1.

\section{Author details \\ 'KU Leuven, Laboratory of Molecular and Cellular Signaling, Department Cellular and Molecular Medicine, Campus Gasthuisberg O/N-I bus 802, Herestraat 49, B-3000 Leuven, Belgium. ${ }^{2}$ KU Leuven, Laboratory for Membrane Trafficking, Department of Human Genetics, and VIB-Center for the Biology of Disease, Campus Gasthuisberg, O/N-IV, 7.159, Herestraat 49, 3000 Leuven, Belgium. ${ }^{3}$ Ghent University, Physiology Group, Department of Basic Medical Sciences, 9000 Ghent, Belgium.}

Published: 24 May 2016

\section{References}

1. Klionsky DJ, Baehrecke EH, Brumell JH, Chu CT, Codogno P, Cuervo AM, Debnath J, Deretic V, Elazar Z, Eskelinen EL, et al. A comprehensive glossary of autophagy-related molecules and processes (2nd edition). Autophagy. 2011;7(11):1273-94.

2. Mizushima N, Ohsumi $\mathrm{Y}$, Yoshimori T. Autophagosome formation in mammalian cells. Cell Struct Funct. 2002;27(6):421-9.

3. Klionsky DJ. Autophagy: from phenomenology to molecular understanding in less than a decade. Nat Rev Mol Cell Biol. 2007:8(11):931-7.

4. Liang XH, Jackson S, Seaman M, Brown K, Kempkes B, Hibshoosh H, Levine $B$. Induction of autophagy and inhibition of tumorigenesis by beclin 1. Nature. 1999;402(6762):672-6.

5. Driscoll JJ, Chowdhury RD. Molecular crosstalk between the proteasome, aggresomes and autophagy: translational potential and clinical implications. Cancer Lett. 2012:325(2):147-54.

6. Liu Y, Shoji-Kawata S, Sumpter Jr RM, Wei Y, Ginet V, Zhang L, Posner B, Tran KA, Green DR, Xavier RJ, et al. Autosis is a $\mathrm{Na}^{+}, \mathrm{K}^{+}$-ATPase-regulated form of cell death triggered by autophagy-inducing peptides, starvation, and hypoxiaischemia. Proc Natl Acad Sci U S A. 2013:110(51):20364-71.

7. Kheloufi M, Boulanger CM, Codogno P, Rautou PE. Autosis occurs in the liver of patients with severe anorexia nervosa. Hepatology. 2015:62(2):657-8.

8. Decuypere JP, Ceulemans $\sqcup$, Agostinis P, Monbaliu D, Naesens M, Pirenne J, Jochmans I. Autophagy and the Kidney: Implications for IschemiaReperfusion Injury and Therapy. Am J Kidney Dis. 2015;66(4):699-9.

9. Lamb CA, Dooley HC, Tooze SA. Endocytosis and autophagy: Shared machinery for degradation. Bioessays. 2013;35(1):34-45.

10. Mizushima N, Yoshimori T, Ohsumi Y. The role of Atg proteins in autophagosome formation. Annu Rev Cell Dev Biol. 2011;27:107-32.

11. Green DR, Levine B. To be or not to be? How selective autophagy and cell death govern cell fate. Cell. 2014;157(1):65-75.

12. Mari M, Tooze SA, Reggiori F. The puzzling origin of the autophagosomal membrane. F1000 Biol Rep. 2011:3:25

13. Axe EL, Walker SA, Manifava M, Chandra P, Roderick HL, Habermann A, Griffiths G, Ktistakis NT. Autophagosome formation from membrane compartments enriched in phosphatidylinositol 3-phosphate and dynamically connected to the endoplasmic reticulum. J Cell Biol. 2008;182(4):685-701

14. Hayashi-Nishino M, Fujita N, Noda T, Yamaguchi A, Yoshimori T, Yamamoto A. A subdomain of the endoplasmic reticulum forms a cradle for autophagosome formation. Nat Cell Biol. 2009;11(12):1433-7.

15. Polson HE, de Lartigue J, Rigden DJ, Reedijk M, Urbe S, Clague MJ, Tooze SA. Mammalian Atg18 (WIPI2) localizes to omegasome-anchored phagophores and positively regulates LC3 lipidation. Autophagy. 2010;6(4):506-22.

16. Kang R, Zeh HJ, Lotze MT, Tang D. The Beclin 1 network regulates autophagy and apoptosis. Cell Death Differ. 2011;18(4):571-80.

17. Decuypere JP, Parys JB, Bultynck G. Regulation of the autophagic bcl-2/ beclin 1 interaction. Cells. 2012;1(3):284-312.

18. Russell RC, Tian Y, Yuan H, Park HW, Chang YY, Kim J, Kim H, Neufeld TP, Dillin A, Guan KL. ULK1 induces autophagy by phosphorylating Beclin-1 and activating VPS34 lipid kinase. Nat Cell Biol. 2013:15(7):741-50.

19. Kim J, Kundu M, Viollet B, Guan KL. AMPK and mTOR regulate autophagy through direct phosphorylation of Ulk1. Nat Cell Biol. 2011:13(2):132-41.

20. Shackelford DB, Shaw RJ. The LKB1-AMPK pathway: metabolism and growth control in tumour suppression. Nat Rev Cancer. 2009:9(8):563-75.

21. Feng $Y, H e ~ D$, Yao Z, Klionsky DJ. The machinery of macroautophagy. Cell Res. 2014:24(1):24-41.

22. Dumit VI, Dengjel J. Autophagosomal protein dynamics and influenza virus infection. Front Immunol. 2012:3:43.

23. Kuma A, Hatano M, Matsui M, Yamamoto A, Nakaya H, Yoshimori T, Ohsumi Y, Tokuhisa T, Mizushima N. The role of autophagy during the early neonatal starvation period. Nature. 2004;432(7020):1032-6.

24. Komatsu M, Waguri S, Ueno T, Iwata J, Murata S, Tanida I, Ezaki J, Mizushima N, Ohsumi Y, Uchiyama Y, et al. Impairment of starvationinduced and constitutive autophagy in Atg7-deficient mice. J Cell Biol. 2005:169(3):425-34.

25. Nishida Y, Arakawa S, Fujitani K, Yamaguchi H, Mizuta T, Kanaseki T, Komatsu M. Otsu K, Tsujimoto Y, Shimizu S. Discovery of Atg5/Atg7-independent alternative macroautophagy. Nature. 2009;461(7264):654-8.

26. Mizushima N, Yoshimori T. How to interpret LC3 immunoblotting. Autophagy. 2007;3(6):542-5. 
27. Klionsky DJ, Abdalla FC, Abeliovich H, Abraham RT, Acevedo-Arozena A, Adeli K, Agholme L, Agnello M, Agostinis P, Aguirre-Ghiso JA, et al. Guidelines for the use and interpretation of assays for monitoring autophagy. Autophagy. 2012;8(4):445-544.

28. Su V, Cochrane K, Lau AF. Degradation of connexins through the proteasomal, endolysosomal and phagolysosomal pathways. J Membr Biol. 2012;245(7):389-400.

29. Falk MM, Fong JT, Kells RM, O'Laughlin MC, Kowal TJ, Thevenin AF. Degradation of endocytosed gap junctions by autophagosomal and endo-/ lysosomal pathways: a perspective. J Membr Biol. 2012;245(8):465-76.

30. Su V, Lau AF. Connexins: mechanisms regulating protein levels and intercellular communication. FEBS Lett. 2014;588(8):1212-20.

31. Falk MM, Kells RM, Berthoud VM. Degradation of connexins and gap junctions. FEBS Lett. 2014;588(8):1221-9.

32. D'hondt C, Ponsaerts R, De Smedt H, Bultynck G, Himpens B. Pannexins, distant relatives of the connexin family with specific cellular functions? Bioessays. 2009;31(9):953-74.

33. Siebert AP, Ma Z, Grevet JD, Demuro A, Parker I, Foskett JK. Structural and functional similarities of calcium homeostasis modulator 1 (CALHM1) ion channe with connexins, pannexins, and innexins. J Biol Chem. 2013;288(9):6140-53.

34. Decrock E, Vinken M, De Vuyst E, Krysko DV, D'herde K, Vanhaecke T, Vandenabeele P, Rogiers V, Leybaert L. Connexin-related signaling in cell death: to live or let die? Cell Death Differ. 2009;16(4):524-36.

35. Leybaert L, Sanderson MJ. Intercellular $\mathrm{Ca}^{2+}$ waves: mechanisms and function. Physiol Rev. 2012;92(3):1359-92.

36. Vinken M, Decrock E, Leybaert L, Bultynck G, Himpens B, Vanhaecke T, Rogiers $V$. Non-channel functions of connexins in cell growth and cell death. Biochim Biophys Acta. 2012;1818(8):2002-8.

37. Elias LA, Wang DD, Kriegstein AR. Gap junction adhesion is necessary for radial migration in the neocortex. Nature. 2007:448(7156):901-7.

38. Garcia-Dorado D, Ruiz-Meana M, Padilla F, Rodriguez-Sinovas A, Mirabet M Gap junction-mediated intercellular communication in ischemic preconditioning. Cardiovasc Res. 2002;55(3):456-65

39. Orellana JA, von Bernhardi R, Giaume C, Saez JC. Glial hemichannels and their involvement in aging and neurodegenerative diseases. Rev Neurosci. 2012;23(2):163-77.

40. Wei CJ, Xu X, Lo CW. Connexins and cell signaling in development and disease. Annu Rev Cell Dev Biol. 2004;20:811-38.

41. Laird DW. Syndromic and non-syndromic disease-linked Cx43 mutations. FEBS Lett. 2014;588(8):1339-48.

42. Molica F, Meens MJ, Morel S, Kwak BR. Mutations in cardiovascular connexin genes. Biol Cell. 2014;106(9):269-93.

43. Kelly JJ, Simek J, Laird DW. Mechanisms linking connexin mutations to human diseases. Cell Tissue Res. 2015;360(3):701-21.

44. Wang N, De Bock M, Decrock E, Bol M, Gadicherla A, Vinken M, Rogiers V, Bukauskas FF, Bultynck G, Leybaert L. Paracrine signaling through plasma membrane hemichannels. Biochim Biophys Acta. 2013;1828(1):35-50.

45. Stehberg J, Moraga-Amaro R, Salazar C, Becerra A, Echeverria C, Orellana JA, Bultynck G, Ponsaerts R, Leybaert L, Simon F, et al. Release of gliotransmitters through astroglial connexin 43 hemichannels is necessary for fear memory consolidation in the basolateral amygdala. FASEB J. 2012;26(9):3649-57.

46. Kar R, Riquelme MA, Werner S, Jiang JX. Connexin 43 channels protect osteocytes against oxidative stress-induced cell death. J Bone Miner Res. 2013;28(7):1611-21.

47. Xu H, Gu S, Riquelme MA, Burra S, Callaway D, Cheng H, Guda T, Schmitz J, Fajardo RJ, Werner SL, et al. Connexin 43 channels are essential for normal bone structure and osteocyte viability. J Bone Miner Res. 2015;30(3):436-48.

48. Zhou JZ, Riquelme MA, Gu S, Kar R, Gao X, Sun L, Jiang JX. Osteocytic connexin hemichannels suppress breast cancer growth and bone metastasis Oncogene. 2016. doi: 10.1038/onc.2016.101.

49. Berthoud VM, Minogue PJ, Laing JG, Beyer EC. Pathways for degradation of connexins and gap junctions. Cardiovasc Res. 2004;62(2):256-67.

50. Solan JL, Lampe PD. Specific Cx43 phosphorylation events regulate gap junction turnover in vivo. FEBS Lett. 2014;588(8):1423-9.

51. Laird DW. Connexin phosphorylation as a regulatory event linked to gap junction internalization and degradation. Biochim Biophys Acta. 2005;1711(2):172-82

52. Falk MM, Baker SM, Gumpert AM, Segretain D, Buckheit 3rd RW. Gap junction turnover is achieved by the internalization of small endocytic double-membrane vesicles. Mol Biol Cell. 2009;20(14):3342-52.
53. Piehl M, Lehmann C, Gumpert A, Denizot JP, Segretain D, Falk MM. Internalization of large double-membrane intercellular vesicles by a clathrin-dependent endocytic process. Mol Biol Cell. 2007;18(2):337-47.

54. Gumpert AM, Varco JS, Baker SM, Piehl M, Falk MM. Double-membrane gap junction internalization requires the clathrin-mediated endocytic machinery. FEBS Lett. 2008;582(19):2887-92.

55. Laing JG, Beyer EC. The gap junction protein connexin43 is degraded via the ubiquitin proteasome pathway. J Biol Chem. 1995;270(44):26399-403.

56. Laing JG, Tadros PN, Green K, Saffitz JE, Beyer EC. Proteolysis of connexin43containing gap junctions in normal and heat-stressed cardiac myocytes. Cardiovasc Res. 1998;38(3):711-8.

57. VanSlyke JK, Musil LS. Dislocation and degradation from the ER are regulated by cytosolic stress. J Cell Biol. 2002;157(3):381-94.

58. Li X, Su V, Kurata WE, Jin C, Lau AF. A novel connexin43-interacting protein, CIP75, which belongs to the UbL-UBA protein family, regulates the turnover of connexin43. J Biol Chem. 2008;283(9):5748-59.

59. Su V, Nakagawa R, Koval M, Lau AF. Ubiquitin-independent proteasomal degradation of endoplasmic reticulum-localized connexin43 mediated by CIP75. J Biol Chem. 2010;285(52):40979-90.

60. Su V, Lau AF. Ubiquitin-like and ubiquitin-associated domain proteins: significance in proteasomal degradation. Cell Mol Life Sci. 2009;66(17):2819-33.

61. Kopanic JL, Schlingmann B, Koval M, Lau AF, Sorgen PL, Su VF. Degradation of gap junction connexins is regulated by the interaction with $\mathrm{C} \times 43-$ interacting protein of 75 kDa (CIP75). Biochem J. 2015;466(3):571-85.

62. Su V, Hoang C, Geerts D, Lau AF. CIP75 (connexin43-interacting protein of $75 \mathrm{kDa}$ ) mediates the endoplasmic reticulum dislocation of connexin43. Biochem J. 2014;458(1):57-67.

63. VanSlyke JK, Deschenes SM, Musil LS. Intracellular transport, assembly, and degradation of wild-type and disease-linked mutant gap junction proteins. Mol Biol Cell. 2000;11(6):1933-46.

64. Kelly SM, Vanslyke JK, Musil LS. Regulation of ubiquitin-proteasome system mediated degradation by cytosolic stress. Mol Biol Cell. 2007;18(11):4279-91.

65. Minogue PJ, Beyer EC, Berthoud VM. A connexin50 mutant, CX50fs, that causes cataracts is unstable, but is rescued by a proteasomal inhibitor. J Biol Chem. 2013;288(28):20427-34.

66. Laing JG, Tadros PN, Westphale EM, Beyer EC. Degradation of connexin43 gap junctions involves both the proteasome and the lysosome. Exp Cell Res. 1997:236(2):482-92.

67. Cochrane K, Su V, Lau AF. The connexin43-interacting protein, CIP85, mediates the internalization of connexin43 from the plasma membrane. Cell Commun Adhes. 2013;20(3-4):53-66.

68. Lan Z, Kurata WE, Martyn KD, Jin C, Lau AF. Novel rab GAP-like protein, CIP85, interacts with connexin43 and induces its degradation. Biochemistry. 2005:44(7):2385-96.

69. VanSlyke JK, Musil LS. Cytosolic stress reduces degradation of connexin43 internalized from the cell surface and enhances gap junction formation and function. Mol Biol Cell. 2005;16(11):5247-57.

70. Lichtenstein A, Minogue PJ, Beyer EC, Berthoud VM. Autophagy: a pathway that contributes to connexin degradation. J Cell Sci. 2011;124(Pt 6):910-20

71. Bejarano E, Girao H, Yuste A, Patel B, Marques C, Spray DC, Pereira P, Cuervo AM. Autophagy modulates dynamics of connexins at the plasma membrane in a ubiquitin-dependent manner. Mol Biol Cell. 2012;23(11):2156-69.

72. Leykauf K, Salek M, Bomke J, Frech M, Lehmann WD, Durst M, Alonso A Ubiquitin protein ligase Nedd4 binds to connexin43 by a phosphorylationmodulated process. J Cell Sci. 2006;119(Pt 17):3634-42.

73. Leithe E, Rivedal E. Ubiquitination of gap junction proteins. J Membr Biol. 2007;217(1-3):43-51.

74. Girao H, Catarino S, Pereira P. Eps15 interacts with ubiquitinated $\mathrm{C} \times 43$ and mediates its internalization. Exp Cell Res. 2009;315(20):3587-97.

75. Fong JT, Kells RM, Gumpert AM, Marzillier JY, Davidson MW, Falk MM Internalized gap junctions are degraded by autophagy. Autophagy. 2012:8(5):794-811.

76. Leithe $\mathrm{E}$, Rivedal E. Ubiquitination and down-regulation of gap junction protein connexin-43 in response to 12-0-tetradecanoylphorbol 13-acetate treatment. J Biol Chem. 2004;279(48):50089-96.

77. Leithe E, Kjenseth A, Sirnes S, Stenmark H, Brech A, Rivedal E. Ubiquitylation of the gap junction protein connexin-43 signals its trafficking from early endosomes to lysosomes in a process mediated by Hrs and Tsg101. J Cell Sci. 2009;122(Pt 21):3883-93. 
78. Carette D, Gilleron J, Denizot JP, Grant K, Pointis G, Segretain D. New cellular mechanisms of gap junction degradation and recycling. Biol Cell. 2015; 107(7):218-31.

79. Ek JF, Delmar M, Perzova R, Taffet SM. Role of histidine 95 on $\mathrm{pH}$ gating of the cardiac gap junction protein connexin43. Circ Res. 1994;74(6):1058-64.

80. Reed AM, Kolodecik T, Husain SZ, Gorelick FS. Low pH enhances connexin32 degradation in the pancreatic acinar cell. Am J Physiol Gastrointest Liver Physiol. 2014;307(1):G24-32.

81. Hesketh GG, Shah MH, Halperin VL, Cooke CA, Akar FG, Yen TE, Kass DA, Machamer CE, Van Eyk JE, Tomaselli GF. Ultrastructure and regulation of lateralized connexin43 in the failing heart. Circ Res. 2010;106(6):1153-63.

82. Ma S, Wang Y, Chen Y, Cao F. The role of the autophagy in myocardial ischemia/reperfusion injury. Biochim Biophys Acta. 2015; 1852(2):271-6

83. Czaja MJ, Ding WX, Donohue Jr TM, Friedman SL, Kim JS, Komatsu M, Lemasters JJ, Lemoine A, Lin JD, Ou JH, et al. Functions of autophagy in normal and diseased liver. Autophagy. 2013;9(8):1131-58.

84. Decuypere JP, Pirenne J, Jochmans I. Autophagy in renal ischemiareperfusion injury: friend or foe? Am J Transplant. 2014;14(6):1464-5.

85. Liu Y, Levine B. Autosis and autophagic cell death: the dark side of autophagy. Cell Death Differ. 2015;22(3):367-76.

86. Martins-Marques T, Catarino S, Zuzarte M, Marques C, Matafome P Pereira P, Girao H. Ischaemia-induced autophagy leads to degradation of gap junction protein connexin43 in cardiomyocytes. Biochem J. 2015;467(2):231-45.

87. Liaw NY, Hoe LS, Sheeran FL, Peart JN, Headrick JP, Cheung MM, Pepe S. Postnatal shifts in ischemic tolerance and cell survival signaling in murine myocardium. Am J Physiol Regul Integr Comp Physiol. 2013; 305(10):R1171-1181

88. Galluzzi L, Pietrocola F, Bravo-San Pedro JM, Amaravadi RK, Baehrecke EH, Cecconi F, Codogno P, Debnath J, Gewirtz DA, Karantza V et al. Autophagy in malignant transformation and cancer progression. EMBO J. 2015;34(7):856-80.

89. White E. The role for autophagy in cancer. J Clin Invest. 2015;125(1):42-6.

90. Sin WC, Crespin S, Mesnil M. Opposing roles of connexin43 in glioma progression. Biochim Biophys Acta. 2012;1818(8):2058-67.

91. Czyz J, Szpak K, Madeja Z. The role of connexins in prostate cancer promotion and progression. Nat Rev Urol. 2012;9(5):274-82.

92. Gilleron J, Carette D, Chevallier D, Segretain D, Pointis G. Molecular connexin partner remodeling orchestrates connexin traffic: from physiology to pathophysiology. Crit Rev Biochem Mol Biol. 2012;47(5):407-23.

93. Leithe E, Sirnes S, Omori Y, Rivedal E. Downregulation of gap junctions in cancer cells. Crit Rev Oncog. 2006;12(3-4):225-56.

94. Zhong WQ, Chen G, Zhang W, Xiong XP, Ren JG, Zhao Y, Liu B, Zhao YF. Down-regulation of connexin43 and connexin32 in keratocystic odontogenic tumours: potential association with clinical features. Histopathology. 2015;66(6):798-807

95. Tittarelli A, Janji B, Van Moer K, Noman MZ, Chouaib S. The Selective Degradation of Synaptic Connexin-43 by Hypoxia-Induced Autophagy Impairs Natural Killer Cell-Mediated Tumor Cell Killing. J Biol Chem. 2015;290(39):23670-9.

96. Barsoum IB, Koti M, Siemens DR, Graham CH. Mechanisms of hypoxia-mediated immune escape in cancer. Cancer Res. 2014;74(24):7185-90.

97. Nikoletopoulou V, Markaki M, Palikaras K, Tavernarakis N. Crosstalk between apoptosis, necrosis and autophagy. Biochim Biophys Acta. 2013;1833(12):3448-59.

98. Pattingre S, Tassa A, Qu X, Garuti R, Liang XH, Mizushima N, Packer M, Schneider MD, Levine B. Bcl-2 antiapoptotic proteins inhibit Beclin 1-dependent autophagy. Cell. 2005;122(6):927-39.

99. Yonekawa T, Gamez G, Kim J, Tan AC, Thorburn J, Gump J, Thorburn A, Morgan MJ. RIP1 negatively regulates basal autophagic flux through TFEB to control sensitivity to apoptosis. EMBO Rep. 2015;16(6):700-8

100. Green DR. Another face of RIPK1. EMBO Rep. 2015;16(6):674-5.

101. Bray K, Mathew R, Lau A, Kamphorst JJ, Fan J, Chen J, Chen HY, Ghavami A, Stein M, DiPaola RS, et al. Autophagy suppresses RIP kinase-dependent necrosis enabling survival to mTOR inhibition. PLoS One. 2012;7(7):e41831.
102. Gump JM, Staskiewicz L, Morgan MJ, Bamberg A, Riches DW, Thorburn A. Autophagy variation within a cell population determines cell fate through selective degradation of Fap-1. Nat Cell Biol. 2014;16(1):47-54.

103. Hou W, Han J, Lu C, Goldstein LA, Rabinowich H. Autophagic degradation of active caspase-8: a crosstalk mechanism between autophagy and apoptosis. Autophagy. 2010;6(7):891-900.

104. Decrock E, Krysko DV, Vinken M, Kaczmarek A, Crispino G, Bol M, Wang N, De Bock M, De Vuyst E, Naus CC, et al. Transfer of $I_{3}$ through gap junctions is critical, but not sufficient, for the spread of apoptosis. Cell Death Differ. 2012;19(6):947-57.

105. Decrock E, De Bock M, Wang N, Gadicherla AK, Bol M, Delvaeye T, Vandenabeele P, Vinken M, Bultynck G, Krysko DV, et al. IP ${ }_{3}$, a small molecule with a powerful message. Biochim Biophys Acta. 2013;1833(7):1772-86.

106. Decrock $E$, Vinken $M$, Bol M, D'herde $K$, Rogiers $V$, Vandenabeele $P$, Krysko DV, Bultynck G, Leybaert L. Calcium and connexin-based intercellular communication, a deadly catch? Cell Calcium. 2011;50(3):310-21

107. Mancuso M, Pasquali E, Leonardi S, Rebessi S, Tanori M, Giardullo P, Borra F, Pazzaglia S, Naus CC, Di Majo V, et al. Role of connexin43 and ATP in long-range bystander radiation damage and oncogenesis in vivo. Oncogene. 2011;30(45):4601-8.

108. Kroemer G. Autophagy: a druggable process that is deregulated in aging and human disease. J Clin Invest. 2015;125(1):1-4.

109. Rubinsztein DC, Bento CF, Deretic V. Therapeutic targeting of autophagy in neurodegenerative and infectious diseases. J Exp Med. 2015;212(7):979-90.

110. Brisset AC, Isakson BE, Kwak BR. Connexins in vascular physiology and pathology. Antioxid Redox Signal. 2009;11(2):267-82.

111. Maes M, Crespo Yanguas S, Willebrords J, Cogliati B, Vinken M. Connexin and pannexin signaling in gastrointestinal and liver disease. Transl Res. 2015:166(4):332-43.

112. Retamal MA, Froger N, Palacios-Prado N, Ezan P, Saez PJ, Saez JC, Giaume C. Cx43 hemichannels and gap junction channels in astrocytes are regulated oppositely by proinflammatory cytokines released from activated microglia. J Neurosci. 2007;27(50):13781-92.

113. Orellana JA, Froger N, Ezan P, Jiang JX, Bennett MV, Naus CC, Giaume C, Saez JC. ATP and glutamate released via astroglial connexin 43 hemichannels mediate neuronal death through activation of pannexin 1 hemichannels. J Neurochem. 2011;118(5):826-40

114. Orellana JA, Shoji KF, Abudara V, Ezan P, Amigou E, Saez PJ, Jiang JX, Naus CC, Saez JC, Giaume C. Amyloid beta-induced death in neurons involves glial and neuronal hemichannels. J Neurosci. 2011;31(13):4962-77.

115. Bejarano E, Yuste A, Patel B, Stout Jr RF, Spray DC, Cuervo AM. Connexins modulate autophagosome biogenesis. Nat Cell Biol. 2014;16(5):401-14.

116. Yamamoto H, Kakuta S, Watanabe TM, Kitamura A, Sekito T, Kondo-Kakuta C, Ichikawa R, Kinjo M, Ohsumi Y. Atg9 vesicles are an important membrane source during early steps of autophagosome formation. J Cell Biol. 2012;198(2):219-33.

117. Criollo A, Maiuri MC, Tasdemir E, Vitale I, Fiebig AA, Andrews D, Molgo J, Diaz J, Lavandero S, Harper F, et al. Regulation of autophagy by the inositol trisphosphate receptor. Cell Death Differ. 2007;14(5):1029-39.

118. Vicencio JM, Ortiz C, Criollo A, Jones AW, Kepp O, Galluzzi L, Joza N, Vitale I, Morselli $E$, Tailler M, et al. The inositol 1,4,5-trisphosphate receptor regulates autophagy through its interaction with Beclin 1. Cell Death Differ. 2009;16(7):1006-17.

119. Criollo A, Vicencio JM, Tasdemir E, Maiuri MC, Lavandero S, Kroemer G. The inositol trisphosphate receptor in the control of autophagy. Autophagy. 2007;3(4):350-3

120. Decuypere JP, Welkenhuyzen K, Luyten T, Ponsaerts R, Dewaele M, Molgo J, Agostinis $P$, Missiaen L, De Smedt $H$, Parys JB, et al. Ins $(1,4,5) P_{3}$ receptormediated $\mathrm{Ca}^{2+}$ signaling and autophagy induction are interrelated. Autophagy. 2011;7(12):1472-89.

121. Decuypere JP, Bultynck G, Parys JB. A dual role for $\mathrm{Ca}^{2+}$ in autophagy regulation. Cell Calcium. 2011;50(3):242-50.

122. Parys JB, Decuypere JP, Bultynck G. Role of the inositol 1,4,5-trisphosphate receptor/ $\mathrm{Ca}^{2+}$-release channel in autophagy. Cell Commun Signal. 2012;10(1):17.

123. Decuypere JP, Kindt D, Luyten T, Welkenhuyzen K, Missiaen L, De Smedt H, Bultynck G, Parys JB. mTOR-Controlled Autophagy Requires Intracellular $\mathrm{Ca}^{2+}$ Signaling. PLoS One. 2013;8(4):e61020. 
124. Sun LQ, Gao JL, Cui CM, Cui Y, Jing XB, Zhao MM, Wang YC, Tian YX, Wang $\mathrm{KJ}$, Cui JZ. Astrocytic p-connexin 43 regulates neuronal autophagy in the hippocampus following traumatic brain injury in rats. Mol Med Rep. 2014:9(1):77-82.

125. Sun L, Gao J, Zhao M, Cui J, Li Y, Yang X, Jing X, Wu Z. A novel cognitive impairment mechanism that astrocytic $\mathrm{p}$-connexin 43 promotes neuronic autophagy via activation of P2X7R and down-regulation of GLT-1 expression in the hippocampus following traumatic brain injury in rats. Behav Brain Res. 2015;291:315-24.

Submit your next manuscript to BioMed Central and we will help you at every step:

- We accept pre-submission inquiries

- Our selector tool helps you to find the most relevant journal

- We provide round the clock customer support

- Convenient online submission

- Thorough peer review

- Inclusion in PubMed and all major indexing services

- Maximum visibility for your research

Submit your manuscript at www.biomedcentral.com/submit
Biomed Central 